\title{
DSM-V: modifying the postpartum-onset specifier to include hypomania
}

\author{
Verinder Sharma • Vivien K. Burt
}

Received: 22 January 2010 / Accepted: 9 September 2010 /Published online: 25 September 2010

(C) The Author(s) 2010. This article is published with open access at Springerlink.com

\begin{abstract}
By failing to include it under the rubric of the postpartum-onset specifier, Diagnostic and Statistical Manual of Mental Disorders (DSM)-IV-TR has ignored the clinical reality that childbirth is a potent trigger of hypomania. Given the serious and occasionally tragic consequences of misdiagnosis of bipolar II depression as unipolar depression in the postpartum period, it is argued that DSM-V should consider modifying the postpartumonset specifier to include episodes of hypomania.
\end{abstract}

Keywords Hypomania · Childbirth · Classification · Bipolar disorder

\footnotetext{
V. Sharma $(\bowtie)$

Department of Psychiatry, University of Western Ontario, London, ON, Canada

e-mail: vsharma@uwo.ca

\section{Sharma}

Department of Obstetrics and Gynecology, University of Western Ontario,

London, ON, Canada

\section{Sharma}

Perinatal Clinic, St. Joseph's Health Care,

London, ON, Canada

V. K. Burt

Department of Psychiatry,

Geffen School of Medicine at UCLA,

Los Angeles, CA, USA

V. K. Burt

Women's Life Center,

Resnick Neuropsychiatric Hospital at UCLA,

Los Angeles, CA, USA
}

\section{Introduction}

With Diagnostic and Statistical Manual of Mental Disorders (DSM)-V scheduled to be published in 2012, efforts are underway to revise DSM-IV-TR (APA 2000). There is general agreement that DSM-IV-TR requires major revisions in format and content to make diagnoses including the specifiers more scientifically valid and clinically relevant (Colom and Vieta 2009). The DSM-IV-TR episode and course specifiers (also known as modifiers) provide a means of establishing sub-categories or variants within the psychiatric disorders and thus provide useful clinical information about anticipated illness course, prognosis, and selection of appropriate treatments.

The postpartum disorders have traditionally been classified as the maternity blues, postpartum depression and postpartum psychosis. DSM-IV-TR does not recognize postpartum disorders as distinct diagnostic entities, but in the text it does acknowledge that among women with postpartum mood or psychotic episodes there are certain symptoms that are more likely to occur (APA 2000). These include mood fluctuations, mood lability, and preoccupation with infant well-being ranging from over-concern to frank delusions. There is also some evidence that postpartum episodes are more likely to be characterized by psychotic features among women with a family history of bipolar disorder. Women with postpartum major depressive episode often have severe anxiety that manifests in the form of a fear of being alone with the infant, or over-intrusiveness that affects the development of a mother/infant relationship.

The postpartum-onset specifier can be applied to the current or most recent depressive, manic, or mixed episode in major depressive disorder, bipolar I disorder, bipolar II disorder, or brief psychotic disorder if the onset of the 
episode is within 4 weeks postpartum (APA 2000). Postpartum-onset is an important course marker for bipolar versus unipolar depression (Ghaemi et al. 2008). However, the postpartum-onset specifier cannot be used to denote a hypomanic episode. This omission is surprising for several reasons. Firstly, there is accumulating evidence that most of bipolarity including that in the postpartum period exists beyond the realm of bipolar I disorder. Secondly, hypomanic symptoms are particularly common in the early puerperium but are often overlooked due to lack of awareness. Thirdly, the consequences of misdiagnosing bipolar II disorder as major depressive disorder can be particularly catastrophic in the postpartum period due to the high risk of suicide and infanticide.

\section{Prevalence of bipolar spectrum disorder}

The term bipolar spectrum disorder generally includes bipolar I disorder, bipolar II disorder, and bipolar disorder not otherwise specified. Bipolar I disorder is characterized by recurrent episodes of mania and depression, while bipolar II disorder is marked by recurrent episodes of hypomania and depression. Patients with bipolar disorder not otherwise specified also have symptoms of depression and mania but these don't reach the DSM-IV threshold criteria for bipolar I or II disorder. DSM-IV-TR reports a lifetime community prevalence of $0.5 \%$ for bipolar II disorder but more recent studies have shown a higher prevalence of bipolarity beyond bipolar I disorder. The recently published National Comorbidity Survey Replication study for example reported prevalence rates of $1.0 \%$ for bipolar I, $1.1 \%$ for bipolar II, and $2.4 \%$ for bipolar disorder NOS (Merikangas et al. 2007). Angst and colleagues reported that the total prevalence of the bipolar spectrum was about $11 \%$, which is similar to that of major depressive disorder. Among outpatients with major depression, $25 \%$ to $50 \%$ have been found to have bipolar disorder (Angst et al. 2003). Using the Structured Clinical Interview for DSM-IV, Sharma et al. (2008) reported that $54 \%$ of patients with postpartum depression had a lifetime diagnosis of bipolar spectrum disorder; however, only a small number $(10 \%)$ of these patients reported receiving a previous diagnosis of bipolar disorder

\section{Ubiquity of postpartum hypomania}

Similar to a dramatic rise in the incidence of manic, depressive and psychotic episodes, hypomanic symptoms are a common occurrence in the postpartum period. Estimates of the prevalence of postpartum hypomania in non-clinical populations have ranged from $9.6 \%$ to $20.4 \%$ on day 3 postpartum (Webster et al. 2003; Farías et al. 2007; Heron et al. 2005; Glover et al. 1994; Lane et al. 1997; Sharma et al. 2009). Symptoms of postpartum hypomania are similar to the symptoms of non-puerperal hypomanic episodes and include elation, increased goaldirected activity, over-talkativeness, racing thoughts, decreased sleep requirement, distractibility, and irritability. Childbirth appears to be a specific trigger for hypomanic symptoms, as the prevalence of hypomania is eightfold higher in the first week after delivery than during pregnancy. By contrast, the prevalence of depression does not significantly increase from pregnancy to the postpartum period (Heron et al. 2009).

\section{Diagnostic and treatment issues}

Bipolar I disorder is a reliable and relatively stable diagnostic category but there is controversy surrounding the diagnosis of bipolar II disorder and bipolar disorder NOS. Bipolar II disorder and bipolar disorder NOS are often under-diagnosed or misdiagnosed as major depressive disorder but there are also concerns about the over-diagnosis of bipolar disorder (Zimmerman et al. 2010). Unfortunately the question of whether bipolar disorder is under-diagnosed or overdiagnosed in the postpartum period has not been studied.

Hypomanic episodes tend to cluster during the early postpartum period as there is a higher incidence during the first 5 days post-delivery (Glover et al. 1994; Lane et al. 1997; Heron et al. 2009), with about $50 \%$ of women with hypomania reporting onset of symptoms on day 1 (Glover et al. 1994), and a significant decrease in hypomanic symptoms at 6-8 weeks postpartum (Glover et al. 1994; Lane et al. 1997; Heron et al. 2009). Diagnosing hypomania can be particularly challenging in the postpartum period due to the difficulty of differentiating it from normal happiness accompanying childbirth. Decreased sleep requirement, a common symptom of hypomania, may be difficult to distinguish from post-delivery sleep changes in women. By itself, postpartum hypomania causes no significant impairment in social or occupational functioning. The clinical significance lies in its association with later postnatal depression. Glover et al. (1994) reported that $50 \%$ of women with the "highs" (postpartum hypomania) developed a probable depression compared to $18 \%$ of women with absence of psychopathology at day 3 postpartum.

Perhaps the main reason for the neglect of bipolar II postpartum depression is the absence of hypomania from the DSM-IV-TR postpartum-onset specifier. Failure to detect hypomanic symptoms frequently results in bipolar postpartum depression being misdiagnosed as major depressive disorder (Ghaemi et al. 2001). The consequences of 
misdiagnosis can be particularly serious in the postpartum period. The use of antidepressants may precipitate mania or a mixed state and thereby increase the risk of further disability and possibly psychiatric hospitalization at a crucial time in a mother's life. There is also a concern that antidepressants are not as effective in the treatment of bipolar depression as in major depressive disorder. Failure to recognize the bipolar diathesis of postpartum depression can thus lead to treatment refractoriness and chronicity. More importantly, the unopposed use of antidepressants in women with bipolar disorder may increase the risk of suicide (Akiskal et al. 2005) and infanticide (Kim et al. 2008). Unfortunately, despite data supporting high attendant morbidity and mortality, there is a common impression that bipolar II disorder and bipolar disorder NOS are milder forms of bipolar illness.

\section{Summary}

The existing literature although limited in nature, supports the modification of the postpartum-onset specifier to include hypomania in DSM-V. Clinically, the modified postpartumonset specifier would likely facilitate early detection and diagnosis, as well as appropriate and safe treatment of bipolar II postpartum depression. The identification of women with postpartum-onset hypomania will provide an opportunity to identify mothers at risk for developing early postpartum depression. The prevalent nature of hypomanic symptoms and their close temporal association with delivery should provide an opportunity to increase our understanding of the etiology and pathophysiology of bipolar disorder. Research is needed to further validate postpartum hypomania using a research diagnostic interview as the standard for a diagnosis of bipolar II disorder. As studies on postpartum hypomania have generally focused on a brief period, it is not clear how long women remain at risk of developing hypomania after delivery. Studies of family history, phenomenology, naturalistic outcome, and screening instruments are also needed to enhance our understanding and management of bipolar II depression in the postpartum period.

Acknowledgements The authors would also like to thank the late Ms. Vineeta Kalia for her help in the preparation of this manuscript.

Dr. Sharma has received grant support from, participated on scientific advisory boards for, or served on the speakers bureaus of AstraZeneca, Bristol-Myers Squibb, Eli Lilly, Janssen, Lundbeck, the Ontario Mental Health Foundation, Pfizer, Servier, and the Stanley Foundation.

Dr. Burt has served as an advisor or consultant to, or on the speakers' bureaus of AstraZeneca, Eli Lilly, Noven Pharmaceuticals, Takeda Pharmaceuticals, and Wyeth Ayerst.
Open Access This article is distributed under the terms of the Creative Commons Attribution Noncommercial License which permits any noncommercial use, distribution, and reproduction in any medium, provided the original author(s) and source are credited.

\section{References}

Akiskal H, Benazzi F, Perugi G, Rhimer Z (2005) Agitated unipolar depression re-conceptualized as a depressive mixed state: implications for the antidepressant-suicide controversy. J Affect Disord 85:245-248

American Psychiatric Association (2000) Diagnostic and statistical manual of mental disorders. DSM-IV-TR, 4th edn. APA, Washington, DC

Angst J, Gamma A, Bennazzi F, Adjacic V, Eich D, Rossler W (2003) Toward a redefinition of subthreshold bipolarity: epidemiology and proposed criteria for bipolar-II, minor bipolar disorders and hypomania. J Affect Disord 73:133-146

Colom F, Vieta E (2009) The road to DSM-V. Psychopathology 42:209-218

Farías ME, Wenk E, Cordero M (2007) Adaptación de la Escala Highs para la detección de sintomatología hipomaníaca en el puerperio. Trastor Ánimo 3:27-36

Ghaemi SN, Ko JY, Goodwin FK (2001) The bipolar spectrum and the antidepressant view of the world. J Psychiatr Pract 7:287-297

Ghaemi S, Bauer M, Cassidy F, Malhi G, Mitchell P, Phelps J et al (2008) Diagnostic guidelines for bipolar disorder: a summary of the international society for bipolar disorders diagnostic guidelines task force report. Bipolar Disord 10:117-128

Glover V, Liddle P, Taylor A, Adams D, Sandler M (1994) Mild hypomania (the highs) can be a feature of the first postpartum week. Association with later depression. Br J Psychiatry 164:517-521

Heron J, Craddock N, Jones I (2005) Postnatal euphoria: are 'the highs' an indicator of bipolarity? Bipolar Disord 7:103-110

Heron J, Haque S, Oyebode F, Craddock N, Jones I (2009) A longitudinal study of hypomania and depression symptoms in pregnancy and the postpartum period. Bipolar Disord 11:410-417

Kim JH, Choi SS, Ha K (2008) A closer look at depression in mothers who kill their children: is it unipolar or bipolar depression? J Clin Psychiatry 69:1625-1631

Lane A, Keville R, Morris M, Kinsella A, Turner M, Barry S (1997) Postnatal depression and elation among mothers and their partners: prevalence and predictors. Br J Psychiatry 171:550-555

Merikangas K, Akiskal H, Angst J, Greenberg P, Hirschfeld R, Petukhova $\mathrm{M}$ et al (2007) Lifetime and 12-month prevalence of bipolar spectrum disorder in the national comorbidity survey replication. Arch Gen Psychiatry 64:543-552

Sharma V, Khan M, Corpse C, Sharma P (2008) Missed bipolarity and psychiatric comorbidity in women with postpartum depression. Bipolar Disord 10:742-747

Sharma V, Burt V, Ritchie HL (2009) Bipolar II postpartum depression: detection, diagnosis, and treatment. Am J Psychiatry 166:1217-1221

Webster J, Pritchard MA, Creedy D, East C (2003) A simplified predictive index for the detection of women at risk for postnatal depression. Birth 30:101-108

Zimmerman M, Galione JN, Ruggero CJ, Chelminski I, Dalrymple K, Young D (2010) Overdiagnosis of bipolar disorder and disability payments. J Nerv Ment Dis 198:452-454 